\title{
Endometriosis-associated ovarian carcinomas: insights into pathogenesis, diagnostics, and therapeutic targets - a narrative review
}

\author{
Eleftherios P. Samartzis ${ }^{1}$, S. Intidhar Labidi-Galy ${ }^{2,3}$, Michele Moschetta ${ }^{4}$, Mario Uccello ${ }^{5}$, \\ Dimitrios R. Kalaitzopoulos ${ }^{1,6}$, J. Alejandro Perez-Fidalgo ${ }^{7}$, Stergios Boussios, ${ }^{8,9}$
}

${ }^{1}$ Department of Gynecology and Gynecological Cancer Center, University Hospital Zurich, Zurich, Switzerland; ${ }^{2}$ Department of Oncology, Hôpitaux Universitaires de Genève, Geneva, Switzerland; ${ }^{3}$ Department of Medicine, Faculty of Medicine, University of Geneva, Geneva, Switzerland; ${ }^{4}$ Cambridge University Hospitals NHS Foundation Trust, Cambridge, UK; ${ }^{5}$ Northampton General Hospital NHS Trust, Cliftonville, Northampton, UK; ${ }^{6}$ Department of Gynecology and Obstetrics, Kantonsspital Schaffhausen, Schaffhausen, Switzerland; ${ }^{7}$ Department of Medical Oncology, Hospital Clinico Universitario de Valencia, INCLIVA, CIBERONC, Valencia, Spain; ${ }^{8}$ Department of Medical Oncology, Medway NHS Foundation Trust, Gillingham, Kent, UK; ${ }^{9}$ AELIA Organization, 9th Km Thessaloniki - Thermi, Thessaloniki, Greece

Contributions: (I) Conception and design: EP Samartzis, S Boussios; (II) Administrative support: All authors; (III) Provision of study materials or patients: All authors; (IV) Collection and assembly of data: All authors; (V) Data analysis and interpretation: All authors; (VI) Manuscript writing: All authors; (VII) Final approval of manuscript: All authors.

Correspondence to: Eleftherios P. Samartzis, MD. Department of Gynecology and Gynecological Cancer Center, University Hospital Zurich, Frauenklinikstrasse 10, CH-8091 Zurich, Switzerland. Email: eleftherios.samartzis@usz.ch.

\begin{abstract}
Endometriosis is a benign gynecologic condition affecting up to one woman out of ten of reproductive age. It is defined by the presence of endometrial-like tissue in localizations outside of the uterine cavity. It often causes symptoms such as chronic pain, most frequently associated with the menstrual cycle, and infertility, but may also be oligo- or asymptomatic. There is evidence that some ovarian carcinoma (OC) histotypes, mainly the ovarian clear cell (OCCC) and endometrioid (EnOC) carcinoma, may arise from endometriosis. The most frequent genomic alterations in these carcinomas are mutations in the AT-rich interacting domain containing protein 1A (ARID1A) gene, a subunit of the SWI/SNF chromatin remodeling complex, and alterations in the phosphatidylinositol 3-kinase (PI3K)/AKT/mTOR pathway, which frequently co-occur. In ARID1A deficient cancers preclinical experimental data suggest different targetable mechanisms including epigenetic regulation, cell cycle, genomic instability, the PI3K/AKT/mTOR pathway, inflammatory pathways, immune modulation, or metabolic alterations as potential precision oncology approaches. Most of these strategies are relying on the concept of synthetic lethality in which tumors deficient in ARID1A are more sensitive to the different compounds. Some of these approaches are currently being or have recently been investigated in early clinical trials. The remarkably frequent occurrence of these mutations in endometriosisassociated ovarian cancer, the occurrence in a relatively young population, and the high proportion of platinumresistant disease certainly warrants further investigation of precision oncology opportunities in this population. Furthermore, advanced knowledge about oncogenic mutations involved in endometriosis-associated ovarian carcinomas may be potentially useful for early cancer detection. However, this approach may be complicated by the frequent occurrence of somatic mutations in benign endometriotic tissue as recent studies suggest. In this narrative review of the current literature, we will discuss the data available on endometriosis-associated ovarian carcinoma, with special emphasis on epidemiology, diagnosis and molecular changes that could have therapeutic implications and clinical applicability in the future.
\end{abstract}

Keywords: Ovarian cancer; endometriosis; clear cell ovarian carcinoma; endometrioid ovarian carcinoma; ARID1A mutations; PI3K/AKT/mTOR pathway; synthetic lethality; treatment; SWI/SNF transcription complex Submitted Apr 02, 2020. Accepted for publication Nov 04, 2020. 
doi: $10.21037 /$ atm-20-3022a

View this article at: http://dx.doi.org/10.21037/atm-20-3022a

\section{Introduction}

Endometriosis is a benign gynecologic condition affecting up to one woman out of ten of reproductive age. It is characterized by pain associated with the menstrual cycle such as dysmenorrhea, dyspareunia, dyschezia, chronic pelvic pain and/or infertility. The prevalence of endometriosis in women affected by infertility is particularly high, up to $50 \%$. It is an estrogen-dependent disease; therefore, it mainly affects women of reproductive age and manifestations of endometriosis in the postmenopausal age are rare. Nevertheless, certain residues of endometriosis may be found incidentally during surgical procedures (1-4).

There are three clinically distinct forms of endometriosis that may occur in combination: peritoneal endometriosis, which is characterized by endometriotic implants on the surface of the peritoneum and the ovaries, endometriotic ovarian cysts (endometrioma) and deep-infiltrating endometriosis, which is characterized by a complex solid mass comprised of endometriotic and fibromuscular tissue and frequently occurs in the rectovaginal septum. In severe cases of deep-infiltrating endometriosis, possible intestinal or urological complications such as obstruction of the rectosigmoid, bowel infiltration, bladder invasion or ureters' stenosis can occur and often require extensive surgical intervention (5). Laparoscopy represents the gold standard for diagnosis and surgical treatment of endometriosis; however, repeated laparoscopies should be avoided when possible.

Although most women with endometriosis will never suffer from cancer related to this benign disease, evidence suggested that certain epithelial ovarian cancer (EOC) subtypes, specifically ovarian clear cell (OCCC) and endometrioid ovarian (EnOC) carcinoma are directly related to endometriosis. This link between endometriosis and these EOC subtypes has been confirmed at the molecular pathology level through the presence of common mutations in cancer-associated genes (6,7). Atypical endometriosis may be the precursor of these cancers, but is not systematically found in all cases of endometriosisassociated ovarian cancer (EAOC).

The challenges raised by these cancers are: (I) they often affect younger women, to a considerable extent in the age span between 35 and 55 years; (II) sonographic differentiation between benign endometriotic cysts, also called endometrioma or chocolate cysts, and earlystage cystic OCCC or EnOC may be very challenging. A carcinoma may arise from a limited atypical epithelial spot in the interior of an endometrioma and is difficult to recognize by sonography in its early stage. EnOC represent about $10 \%$ of EOC, whereas OCCC, with a prevalence of $5-12 \%$, is geographically more variable and more frequent in some Asian countries. EnOC may be low or high grade, but OCCC is per definition high-grade ovarian carcinoma and has poor prognosis in advanced stages due to early platinum-resistance (8-12).

Benign endometrioma are usually managed surgically while preserving the ovary, either by excision of the cyst or, in cases where a maximum of ovarian tissue has to be preserved to maintain fertility, by fenestration and laser ablation of the inside of the endometrioma, for instance (Figure 1). In contrast, EAOC must obviously be managed surgically by complete salpingo-oophorectomy without opening the cystic lesions to avoid intra-abdominal spillage of malignant cells (Figure 2). These cases necessitate a referral to a center specialized in gynecologic oncology and usually require median laparotomy for staging and resection of any detectable tumor masses, hysterectomy and bilateral salpingo-oophorectomy, omentectomy, and a stage-dependent adequate pelvic and para-aortic lymph node assessment (13-15). In patients with presumable endometriotic cysts, it is crucial to detect the rare cases with increased risk of malignant transformation preoperatively in order to avoid the intraoperative dissemination of malignant cells. This requires a high degree of expertise in transvaginal sonography, which is the most useful and accessible method in preoperative assessment. Magnetic resonance tomography may have additional value in certain cases, but is not a standard procedure for preoperative assessment of endometrioma. Tumor marker CA-125 may be helpful, but its usefulness in the diagnosis of early EAOC is limited due to lack of specificity. Indeed, moderate elevations of CA-125 often occur in women with benign endometriosis without any evidence of EOC (16-22).

In this narrative review of the present literature, we will discuss the data available on EAOC, with special emphasis on epidemiology, diagnosis and molecular changes that have therapeutical implications. As especially OCCC are 


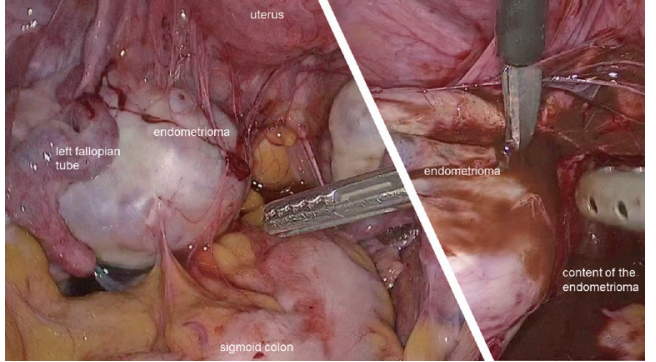

Figure 1 Endometrioma of the left ovary. Endometrioma typically contain brown viscous content resembling to melted chocolate, reason why they are sometimes also called "chocolate cysts". The surgical treatment of choice consists in the laparoscopic excision or fenestration and laser therapy of the cyst with preservation of the ovary (Image credits: with special thanks to Dr. Markus Eberhard, Schaffhausen, Switzerland).

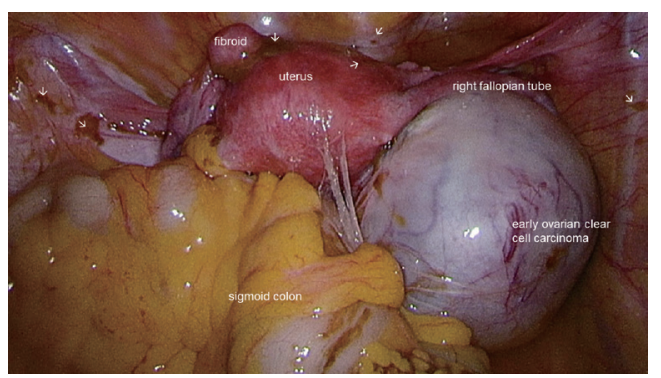

Figure 2 Early ovarian clear cell carcinoma (OCC). Clear cell carcinoma of the right ovary, most probably originating from endometriosis. The macroscopic picture in the very early stage may be difficult to distinguish from a benign endometrioma or another benign ovarian tumor. The preoperative assessment including transvaginal sonography and tumor marker CA-125 is important in the risk assessment (e.g. according to the IOTA criteria) and crucial for the correct surgical therapy of the patient. Arrows: various peritoneal endometriotic lesions and old blood deposits.

often associated with early occuring resistance to platinumbased chemotherapy regimen the rationale is to identify targetable molecular key-mechanisms that provide potential new opportunities in a precision oncology approach. As many of these mechanisms seem to be involved early in the pathogenesis of endometriosis-related ovarian cancer a better understanding may in future also be an opportunity for early cancer detection in these patients.

The objective of the present review is to provide an overview of these key-mechanisms in the development of endometriosis-related ovarian cancer and to discuss them in a possible clinical context based on recent preclinical and early clinical observations.

Scientific articles with relevance for the discussion of the topic were searched using PubMed with emphasis on articles published over the last decade. The data in this review were all obtained from published studies and/or publicly available study information. Only articles published in English language were included. Written general consent of the patients was available for all intraoperative images reproduced in this review article. We present the following article in accordance with the NARRATIVE REVIEW reporting checklist (available at http://dx.doi.org/10.21037/ atm-20-3022a).

\section{Pathogenesis of endometriosis}

Different theories have been proposed regarding pathogenesis of endometriosis since its first modern description by Sampson almost one century ago. There are probably various reasons for the development of endometriosis, such as anatomical variations leading to increased retrograde menstruation, environmental toxins or potent estrogens, especially in case of an in utero exposure, genetic factors as well as inflammatory mediators such as cytokines (3). Most theories regarding pathogenesis of endometriosis consider retrograde menstruation as being one of the principle factors connected to the development of endometriosis. However, retrograde menstruation through the natural orifice of the fallopian tubes is found in most women and is not sufficient to explain why only some women having retrograde menstruation will develop endometriosis. Nor does it explain why endometriosis can develop in patients without patency of the fallopian tubes or after hysterectomy and even in some women with congenital absence of uterus such as the Mayer-RokitanskyKüster-Hauser (MRKH) syndrome (23).

Although endometriosis is regarded as a benign disease, it shares some features that are classic hallmarks of cancer, such as migration and tissue invasion, but in contrast to cancer, the misplaced tissue is morphologically resembling to normal endometrium. Endometriosis can also lead to lymphangiogenesis and endometriotic tissue has been found in lymphatic nodes $(24,25)$. Nevertheless, endometriosis is not lethal and does not metastasize or progress in the form of an expansile tumor mass like cancer (26).

Treatment modalities of endometriosis include surgical excision of endometriotic implants, through laparoscopic approach, and hormonal therapies, mainly progestins 
(e.g., dienogest), GnRH analogs (e.g., goserelin) or $\mathrm{GnRH}$ antagonists (e.g., elagolix). Because endometriosis is a chronic disease, a prolonged hormonal recurrence prophylaxis is necessary, especially in cases with more severe endometriosis and/or associated pain $(2,27)$. The risk for developing ovarian cancer is generally low for women with endometriosis, with a lifetime risk of about $1.9 \%$, but it is relatively increased compared to the general population (lifetime risk of approximately 1.4\%) $(21,28)$.

Recent findings indicate that somatic cancer driver mutations in the ARID1A gene are present in a subset of endometriosis cases and may be involved in its pathogenesis (29-32). Endometriosis is an estrogen-dependent disease. The role of ARID1A mutations in regulating estrogen receptor signaling may further support its relevance in the pathogenesis of endometriosis, as it was recently reported in the context of estrogen-receptor-positive breast cancer $(33,34)$.

\section{Epidemiology of endometriosis-associated ovarian carcinoma}

A possible link between endometriosis and EOC in certain cases has been suggested for a long time. It was Sampson who described for the first time in 1925 an endometriosisassociated ovarian endometrioid carcinoma (35). Multiple studies have since assessed the incidence of EAOC (36-46). In a large register study of 20,686 Swedish women hospitalized for endometriosis, the standardized incidence ratio for developing ovarian cancer during a mean followup of 11.4 years was 1.9 (95\% CI: $1.3-2.8$ ). The risk of ovarian cancer was higher in patients with a long history of endometriosis (47). In another Swedish register study including 64,492 women with endometriosis, the standardized incidence ratio was 1.43 (95\% CI: 1.19-1.71), again with a higher incidence in women with early diagnosis and a long history of endometriosis (48). In a pooled metaanalysis of 13 case-control studies including 7,911 women with ovarian cancer and 13,226 controls, the frequency of self-reported endometriosis was significantly higher in the group with ovarian cancer. This group had an odds ratio (OR) of 1.46 (95\% CI: $1.31-1.63, \mathrm{P}<0.0001)$ after adjustment for the duration of oral contraceptive use as well as parity and stratification for age and ethnic origin. The OR were significantly increased in the histotypes OCCC (OR 3.05, 95\% CI: 2.43-3.84, P<0.0001), EnOC (OR 2.04, 95\% CI: $1.67-2.48, \mathrm{P}<0.0001)$ and low-grade serous carcinoma (OR 2.11, 95\% CI: 1.39-3.20, $\mathrm{P}<0.0001)$. No association between a history of endometriosis and risk for high-grade serous or mucinous carcinoma were found (49). Consistent observations were reported by a Danish register study (OR 1.34, 95\% CI: 1.16-1.55), confirming the association with the two histotypes EnOC (OR 1.64, 95\% CI: 1.09-2.37) and OCCC (OR 3.64, 95\% CI: 2.36-5.38) (50). In the ENOCA population-based cohort study using the Dutch nationwide registry of histopathology and cytopathology, the incidence of endometrioid and clear-cell ovarian cancer in a cohort of 131,450 women with a histological diagnosis of endometriosis was compared to an age-matched control cohort of 132,654 women with a benign dermal nevus. The age-adjusted incidence rate ratio (IRR) was 7.18 (95\% CI: 6.17-8.46) for ovarian cancer in women with endometriosis, and there was a strong association with the two subtypes of OCCC (with an IRR of 21.34, 95\% CI: 14.01-32.51) and EnOC (with an IRR of 29.06, 95\% CI: 20.66-40.87), all of them age adjusted. However, an important subset of these patients had a simultaneous diagnosis of endometriosis and ovarian cancer in the same surgery, which represented a potential bias in the study. Therefore, the authors excluded women with diagnosis of endometriosis less than one year before diagnosis of ovarian cancer in a subsequent analysis. Overall, the recalculated age-adjusted IRR was estimated to be 1.08 (95\% CI: 0.87-1.35) for ovarian cancer, with still a significantly increased risk for the two subtypes of OCCC and EnOC. An important observation in this study was that the median age at diagnosis of ovarian cancer was earlier, with 56 years (IQR 49-63) for women with endometriosis compared to 60 years in the control cohort (IQR 53-67). This observation suggests that women with endometriosis still have an increased risk for developing ovarian cancer even if the activity and symptoms of endometriosis drop after the onset of menopause (51). In contrast to the evident link between endometriosis and ovarian carcinoma, women with endometriosis do not seem to be at increased risk for endometrial cancer, as reported by a large prospective cohort of U.S. nurses (52). The present literature generally does not support an increased risk for cancers other than EOC in women with endometriosis (53).

In summary, the lifetime risk for developing ovarian cancer is low with approximately $1.9 \%$ (as compared to $1.4 \%$ for the general population) since ovarian cancer is not frequent when compared to other cancers (breast, lung, colon, etc...). Nevertheless, the risk for a woman with endometriosis to develop ovarian cancer is up to $50 \%$ higher than in the general population. This is particularly true regarding the risk for developing the clear cell or endometrioid histotype, 
Table 1 Prevalence of ARID1A mutations in different cancers

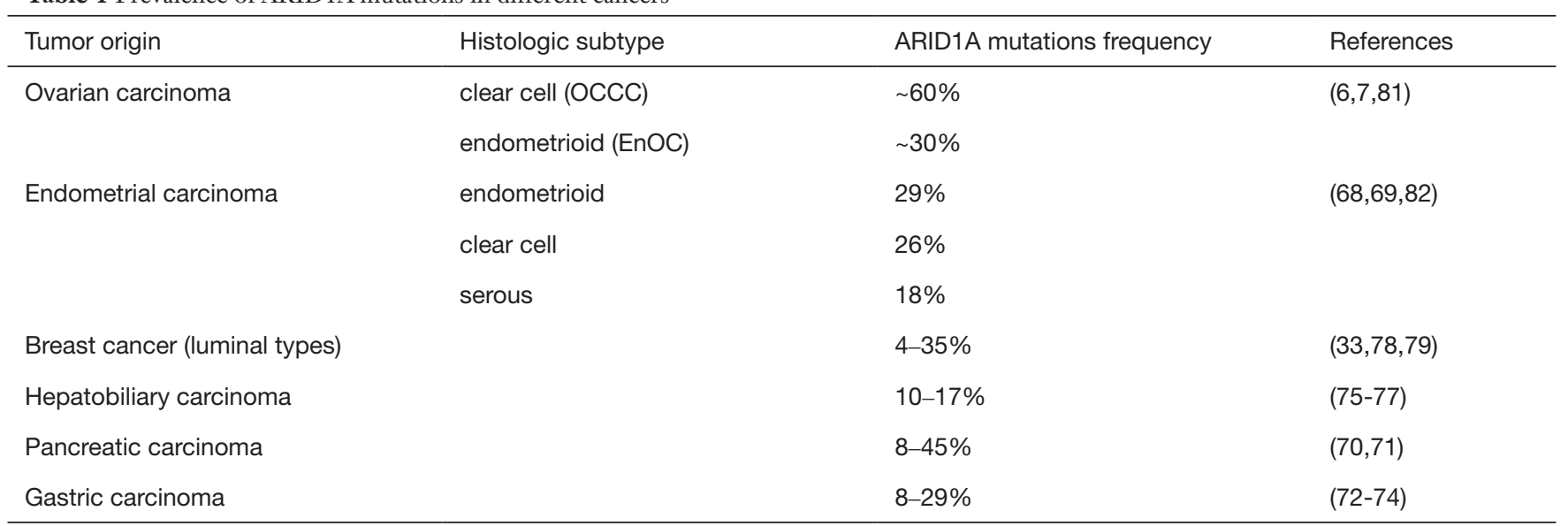

where the risk is tripled or doubled, respectively (21).

\section{Diagnostics in endometriosis and issues for early cancer detection}

Transvaginal sonography is one of the most valuable diagnostic tools in the routine diagnosis of endometrioma and suspicious ovarian masses. It is usually complemented by serum measurement of the tumor marker CA-125 and, in certain circumstances, may be supplemented by other imaging techniques such as magnetic resonance tomography or computer tomography. The sensitivity and specificity of transvaginal sonography is overall comparable to magnetic resonance tomography, and it is usually sufficient for the preoperative assessment of endometrioma and/or suspicious ovarian masses (21).

Recently, the diagnostic possibilities of ultrasound imaging have improved considerably, both regarding technology and assessment expertise of the sonographer. Clinical research collaborations such as the International Ovarian Tumour Analysis (IOTA) group and others have permitted results that were not possible before for ultrasound assessment of suspicious ovarian masses (54-56).

The description of all sonographic criteria that allow preoperative assessment of the risk of malignancy in endometrioma and other masses of the ovary is beyond the scope of this review. It is important to note that a typical endometrioma is mostly a unilocular (or multilocular with up to four locules) cyst containing a homogeneous "groundglass" echogenicity without detectable solid or vascularized papillary parts, whereas borderline tumors and carcinoma arising from endometrioma generally show a vascularized solid component (54). An increased age of 45 years or more as well as increased endometrioma size $(\geq 8 \mathrm{~cm})$ were independent predictors for the development of ovarian cancer in women with endometrioma $(43,57,58)$.

Recent studies have proposed mutation analyses in endocervical or preferably intrauterine cell samples for a potential early detection of endometrial and ovarian cancer. These methods must be further studied regarding their clinical validity. However, even if some of these concepts should prove to be valid for a peri-/postmenopausal population in future, this may likely not be the same for a younger population of patients with endometriosis as somatic mutations occur more frequently in eutopic and ectopic endometrium than previously thought (30,59-62). At present, there is no useful screening possibility for EOC and this also applies to patients with endometriosis (63-66).

\section{Common pathogenic features of endometriosis and associated ovarian carcinoma}

Since the discovery in 2010 that mutations in the $A T$-rich interacting domain $1 A$ (ARID1A), encoding an accessory subunit of the SWI/SNF chromatin remodeling complex, are frequent in OCCC, EnOC and their endometriotic precursor lesions, there has been substantial emphasis on EAOC and the epigenetic role of the SWI/SNF chromatin remodeling complex in carcinogenesis $(6,7)$. Overall, SWI/SNF-associated genes are mutated in about $20 \%$ of all human cancers. Mutations in ARID1A have been found in a multitude of different cancers, with the highest frequency in OCCC (up to 60\%) and EnOC (approx. 30\%) $(6,7,33,34,67-81)$ (Table 1). 


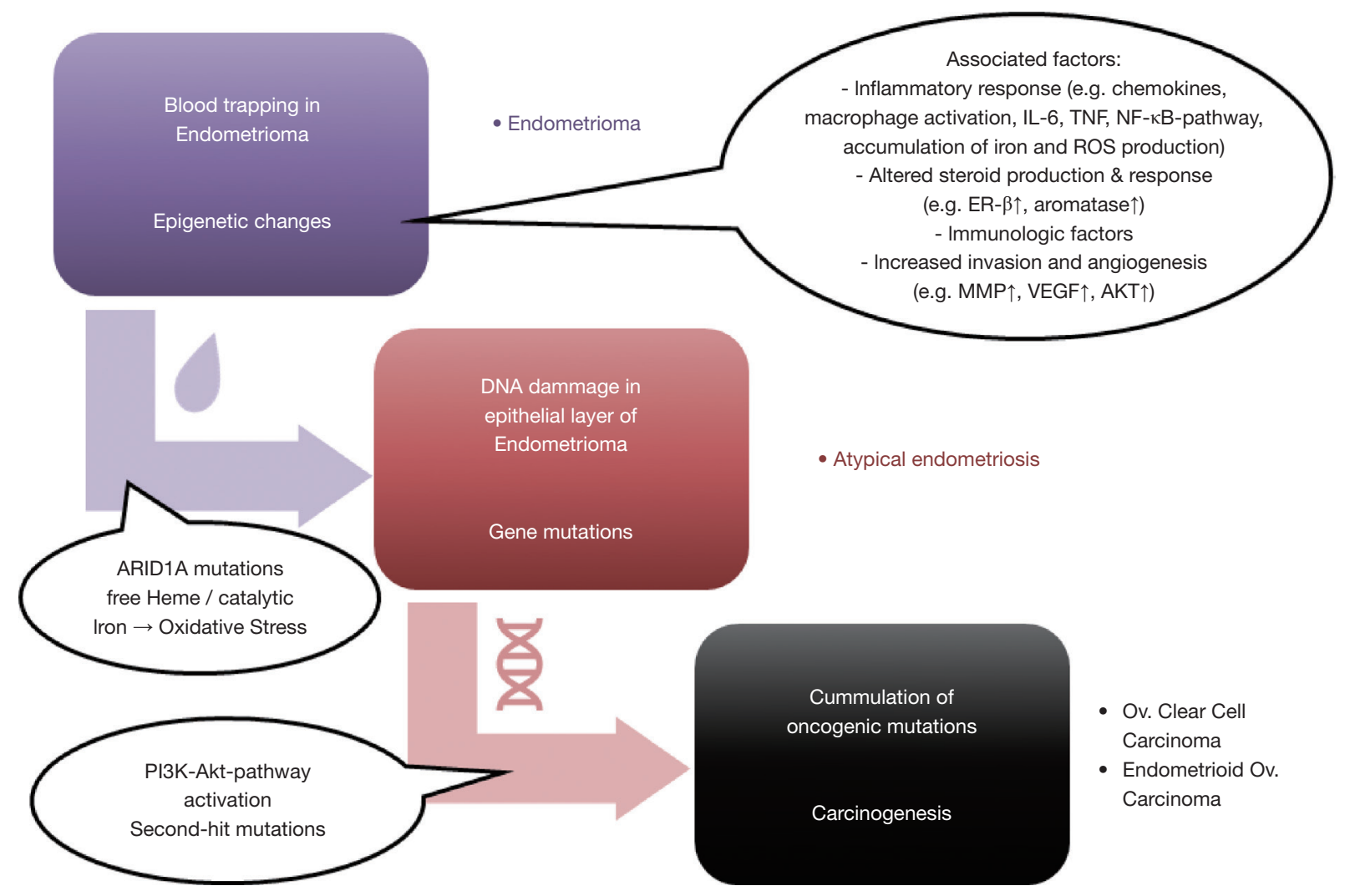

Figure 3 Hypothetic model of pathogenesis of endometriosis-associated ovarian carcinoma. Reactive oxygen species (ROS) due to free heme and catalytic iron contained in the trapped blood in endometriomas may lead to increased oxidative stress and DNA damage in the epithelial layer of endometriomas. This may result in mutations and epigenetic changes, including mutations in the tumor suppressor gene ARID1A and possible second-hit mutations as well as activation of the PI3K-AKT-mTOR pathway to escape apoptosis caused by increased oxidative stress. The accumulation of oncogenic mutations in atypical endometriosis may ultimately lead to the development of endometriosisassociated ovarian clear cell (OCC) and endometrioid (EnOC) carcinomas (adapted from Vercellini et al., Hum Reprod, 2011 and Samartzis et al., GYNÄKOLOGIE, 2018).

The ARID1A gene encodes the protein BRG1associated factor 250a (BAF250a or p270), which is part of a family of 15 human proteins that contain a typical 100-amino-acid DNA-binding ARID domain (83). The SWI/SNF complexes bind to DNA regions via ARID1A or ARID1B, which are two mutually exclusive, nonselective DNA binding accessory subunits of the complex, and/or through interaction with general or specific transcription factors $(84,85)$. Mutations in ARID1A are in general lossof-function mutations, including nonsense, frameshift and large deletions that lead to a loss of BAF250a protein expression (6). Importantly, endometriosis is the first and only benign disease in which a loss of ARID1A expression has been observed in cases without any evidence for cancer (29,30,86-88). Mutations in ARID1A are considered as an early event but ARID1A inactivation alone is not sufficient for the oncogenic transformation of either the endometrium or ovarian surface epithelium. Several other mechanisms such as PIK3CA-activating mutations in cooperation with loss of ARID1A expression seem to be necessary to initiating cancer development (Figure 3) (80,89-94).

Due to its large size (20 exons) and the distribution of mutations across the whole gene, detection of mutations in ARID1A by sequencing is quite challenging, especially when only a very limited amount of tissue is available, which is the case for the epithelial fraction of endometriosis $(6,30)$. ARID1A immunohistochemistry has been shown to be an excellent surrogate marker for ARID1A mutations (95).

Interestingly there are no known mutually exclusive mutations that clearly distinguish OCCC and EnOC, 


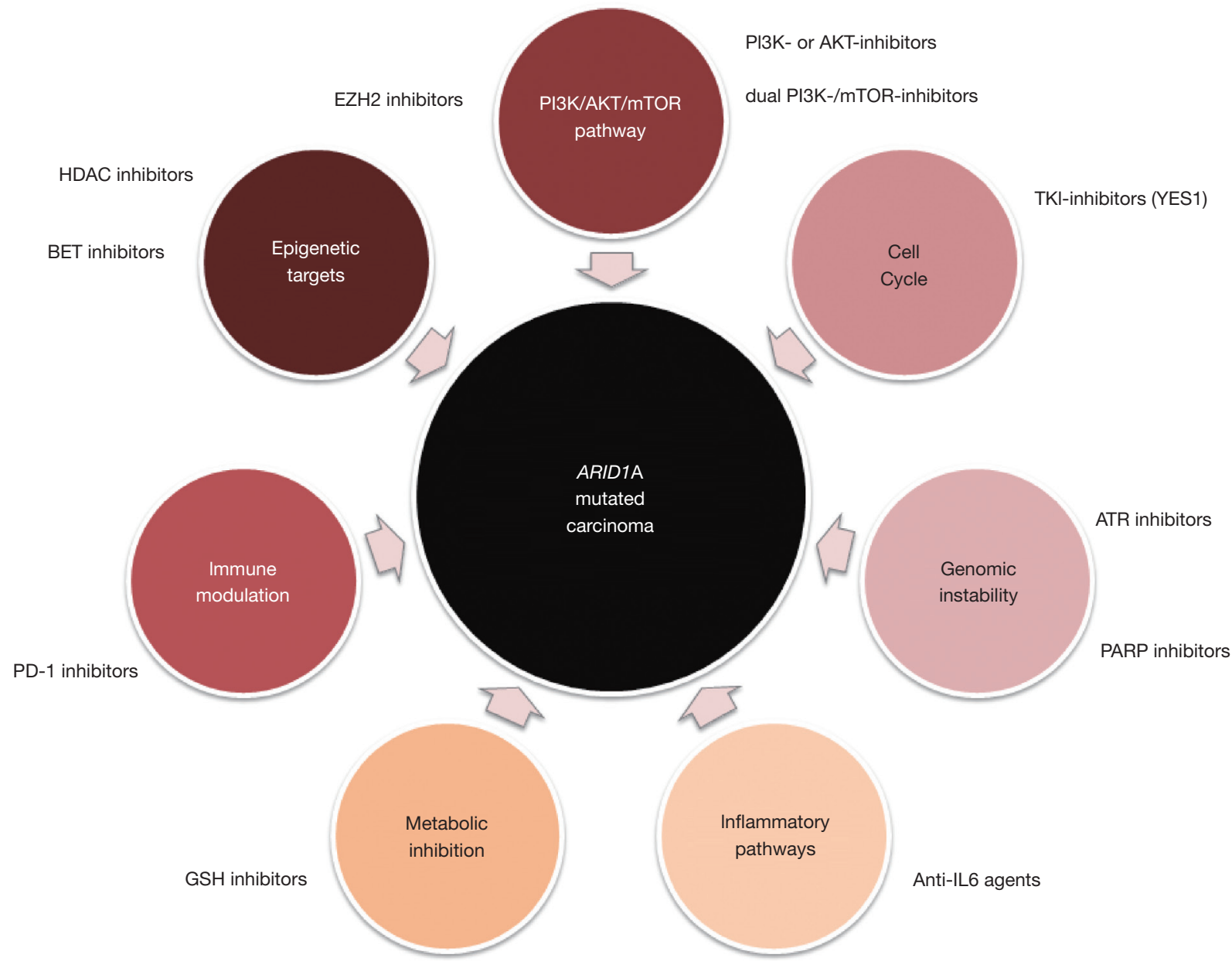

Figure 4 Therapeutic targeting strategies in ARID1A deficient tumors. Since ARID1A mutations lead to a deficiency in the encoded protein, the strategies to target ARID1A mutated tumors use the principle of synthetic lethality. The main approaches are stated in circles and the examples of inhibitor families are listed next to the main groups.

even though these two histotypes are distinct in their morphological and clinical presentation. However, some genomic features such as the APOBEC (apolipoprotein B mRNA editing enzyme catalytic polypeptide-like) signature are found in $26 \%$ of OCCC, whereas microsatellite instability is more frequent $(28 \%)$ in $\mathrm{EnOC}(80,96)$.

\section{Preclinical studies targeting ARID1A-mutated tumors}

Since ARID1A mutations cause loss of functions in a tumorsuppressing mechanism, there is no possibility of directly targeting the mutations with a therapeutic intent (97). Various preclinical studies suggest the possibility of using the synthetic lethality approach, a concept that is best known in PARP-inhibitors, to target ARID1A-deficient tumors (Figure 4) (98-101). A general overview of different preclinically identified therapeutic targets related to ARID1A deficiency is provided in Table 2.

In OCCC, ARID1A mutations frequently co-occur with mutations that lead to the activation of the PI3K/ AKT signaling pathway, such as loss of PTEN (phosphatase and tensin homolog) or gain-of-function mutations of the PIK3CA gene, encoding the catalytic subunit, p110 $\alpha$, of PI3K (91,119). These changes have also been observed in benign and atypical endometriosis adjacent to OCCC $(6,29,61,120)$. These observations suggest a cooperative role of ARID1A inactivation and PI3K/AKT activation in the malignant transformation of the endometriotic precursor lesion. A conditional ARID1A knockout was combined 
Table 2 Potential targets in ARID1A-mutated tumors in preclinical studies

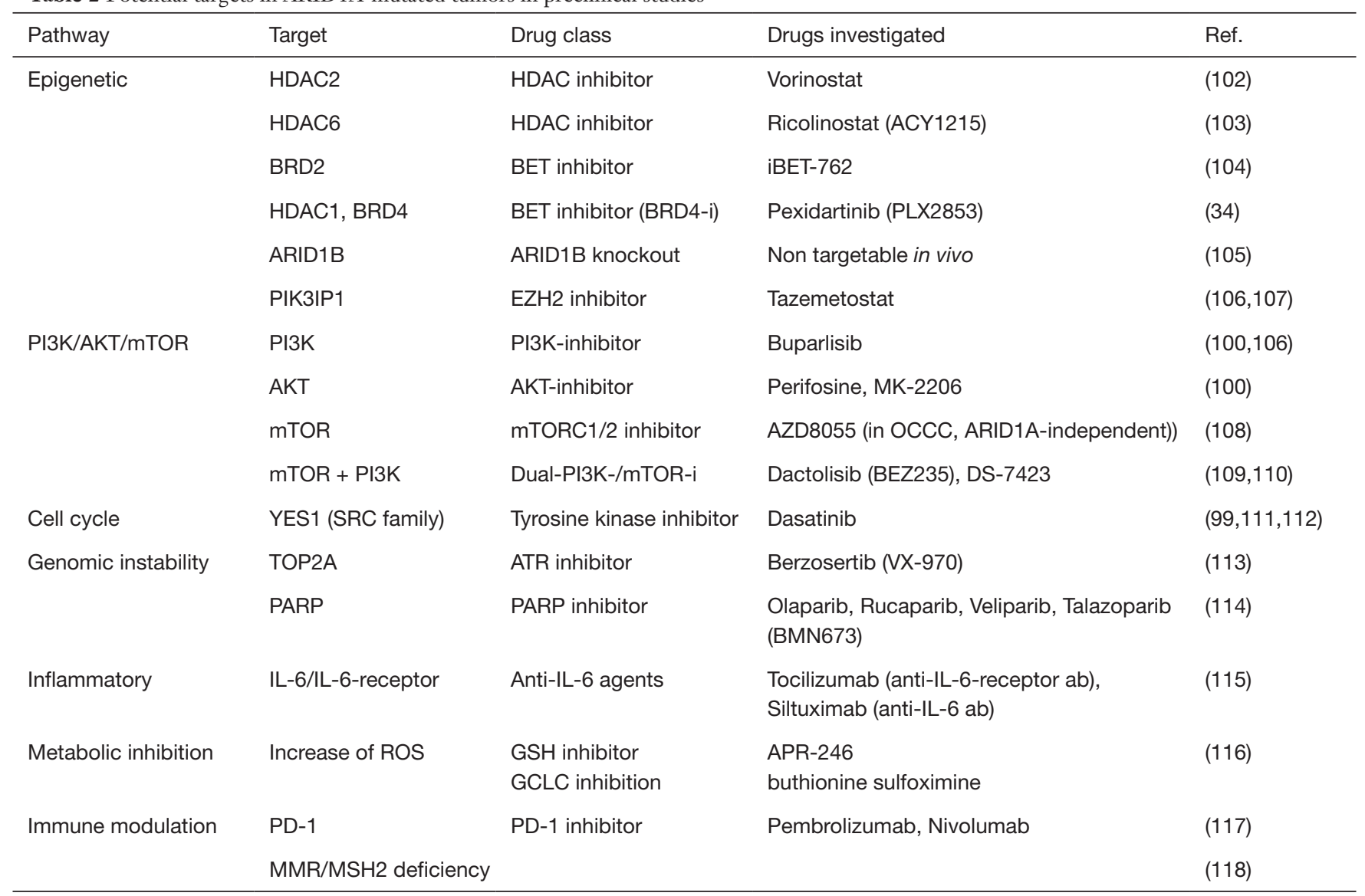

with insertion of a mutant PIK3CA allele in a transgenic mouse model, leading to the expression of a constitutively active catalytic subunit of PI3K and the development of highly penetrant ovarian tumors with OCCC-like histopathology (115). These results affirmed that ARID1A loss and activation of PI3K/AKT functionally cooperate in ovarian carcinogenesis, and suggest that ARID1A-deficient tumors may be "addicted" to PI3K/AKT oncogenic signaling. As a consequence, elements of the PI3K/AKT signaling pathway may be good candidate targets for the induction of synthetic lethality in tumors with ARID1A loss-of-function mutations. In vitro studies have shown increased sensitivity and induced apoptosis towards the AKT-inhibitors MK-2206 and perifosine, as well as the Pan-PI3K-inhibitor buparlisib, in ARID1A-depleted breast cancer and OCCC cell lines $(100,106)$. The mTORC1/2 inhibitor AZD8055 showed a significant sensitivity in OCCC cell lines and patient-derived xenografts which however was independent of the ARID1A mutation status and PI3K/AKT/mTOR alterations (108). EZH2 inhibition led to synthetic lethality in ARID1A-mutated tumors, in which PIK3IP1, an inhibitor of PI3K/Akt, plays a major role $(106,107)$. As another epigenetic target, a lethal relationship was identified between ARID1A loss and inhibition of HDAC6 using the HDAC6-inhibitor ACY1215 (103).

Other in vitro approaches such as the depletion of ARID1B in ARID1A-mutated tumor cells demonstrated strong synthetic lethality, since ARID1A and ARID1B are mutually exclusive subunits of the SWI/SNF complex and the survival of $A R I D 1 A$-deficient cells depends on the presence of ARID1B in the residual SWI/SNF complex (105).

Without a doubt, chronic inflammation is a central process in EAOC, with proinflammatory cytokines playing an important role in benign endometriosis. ARID1A has been shown to protect against inflammation-driven tumorigenesis. The combination of ARID1A loss and 
PIK3CA activating mutations led to the development of OCCC through sustained IL-6 production. Knockdown of IL6 led to significantly smaller tumors. High levels of IL-6, measured in the serum or by IHC are associated with poor outcome in OCCC $(121,122)$. Thus, anti-IL-6 therapies, which are already used in the clinics for rheumatologic disease, may show a potential activity in ARID1A-mutated ovarian cancer (115).

There is evidence suggesting a role of immune checkpoint inhibitors in tumors harboring mutations in components of the SWI/SNF complex. Recent treatment successes have been reported in small-cell carcinoma of the ovary, hypercalcemic type (SCCOHT), which is a highly aggressive monogenic cancer driven by SMARCA4 mutations, affecting the catalytic ATPase subunit SMARCA4/BRG1 of the SWI-SNF complex. These tumors responded well to treatment with anti-PD1 immunotherapy despite a low mutation burden (117). In clear cell renal cell carcinoma, clinical benefit from anti-PD1 was associated with loss-of-function mutations in the PBRM1 gene, which encodes a subunit of the PBAF form of the SWI-SNF complex (123). In the early clinical trials with anti-PD1 in EOC, the highest response rates were observed in OCCC $(124,125)$. Together, these observations support further investigation of immune checkpoint inhibitors in OCCC and the predictive value of ARID1A mutations (117).

Besides genes' regulation, the SWI/SNF complex has a role in the DNA damage repair processes. The complex often localizes to sites of DNA double-strand breaks and facilitates the phosphorylation of histone $\mathrm{H} 2 \mathrm{AX}$ via ATM/ATR (126). Treatment with the ATR-inhibitor berzosertib (VX-970) resulted in more than three times effective response in various $A R I D 1 A$-deficient cell lines including OCCC, and sensitivity towards ATR-inhibition was observed in ARID1A mutant xenograft mouse models. ARID1A loss was shown to result in accumulation of cells in G2/M. Treatment with ATR inhibitors reversed cells accumulation in G2/M and resulted in an increased chromosomal instability and apoptosis (113). It is important to note that ARID1A-deficient tumors counterintuitively typically display less copy number alterations than ARID1A wild-type tumors across various cancer types. This seemingly increased genomic stability is the result of defects in telomere cohesion in ARID1A-deficient tumors leading to a continuous selection process against genetically instable cancer cells and this mechanism amongst others significantly relies on the ATR checkpoint (127).

A drug screening study of 68 clinically approved or late-stage clinically developed inhibitors identified dasatinib, a SRC, ABL and C-KIT inhibitor, as being a specific inhibitor in ARID1Amutated OCCC cell lines. This was confirmed in ARID1A knockout cell lines. The study identified YES1, an SRC family protein, as being the most selective target in ARID1A-deficient OCCC tumor cells. Dasatinib induced cell cycle arrest in G1 and caspase activity in ARID1A-mutant tumor cells (99).

Last but not least, it has been shown that SWI/SNF function is required for oxidative stress resistance $(128,129)$. Oxidative stress induced by reactive oxygen species (ROS) plays an important role through the abundance of free heme and catalytic iron in endometrioma and probably plays a central role in the pathogenesis of EAOC (130). ARID1Amutant OCCC and endometrial cancer cell lines were five to six times more sensitive towards the ROS-inducing agent elesclomol compared to ARID1A-wildtype cancer cell lines, resulting in increased ROS-levels and apoptosis (131). Ogiwara et al. demonstrated a link between ARID1A and glutathione metabolism that is mediated by the regulation of the cystine/glutamate transporter XCT, revealing that decreased glutathione synthesis is a metabolic dependency of cancers with ARID1A-inactivating mutations (116). This complex interaction between epigenetics and the glutathione synthesis metabolic pathway opens new insights into the mechanisms of tumor initiation, progression and drug resistance. This may open great therapeutic opportunities, but the complexity of these interactions will have to be better understood in order to develop properly tailored glutathione synthesis inhibitors $(132,133)$.

\section{Current clinical trials}

Targeting of sustained proliferative pathways, such as the PI3K/AKT/mTOR pathway and the YES1/SRC tyrosine kinase pathway, or metabolic alterations, such as the glutathione biogenesis pathway, in ARID1A-deficient CCOC may be interesting options for future clinical trials (134). Various agents showing synthetic lethality in the ARID1A mutant context are currently in clinical development. An overview of current clinical trials mainly regarding OCCC or relevant for EAOC is available in Table 3. In addition to its potential role as a predictive biomarker in cancer treatments, ARID1A mutations have also been investigated for other purposes such as e.g., early cancer detection or in other biomarker studies (Table 4). Some studies have also assessed ARID1A as a potential prognostic marker in ovarian cancer correlating it to the overall survival and resistance to platinum- 
Table 3 Current clinical trials in gynecological cancer using an ARID1A-related treatment approach (www.clinicaltrials.gov)

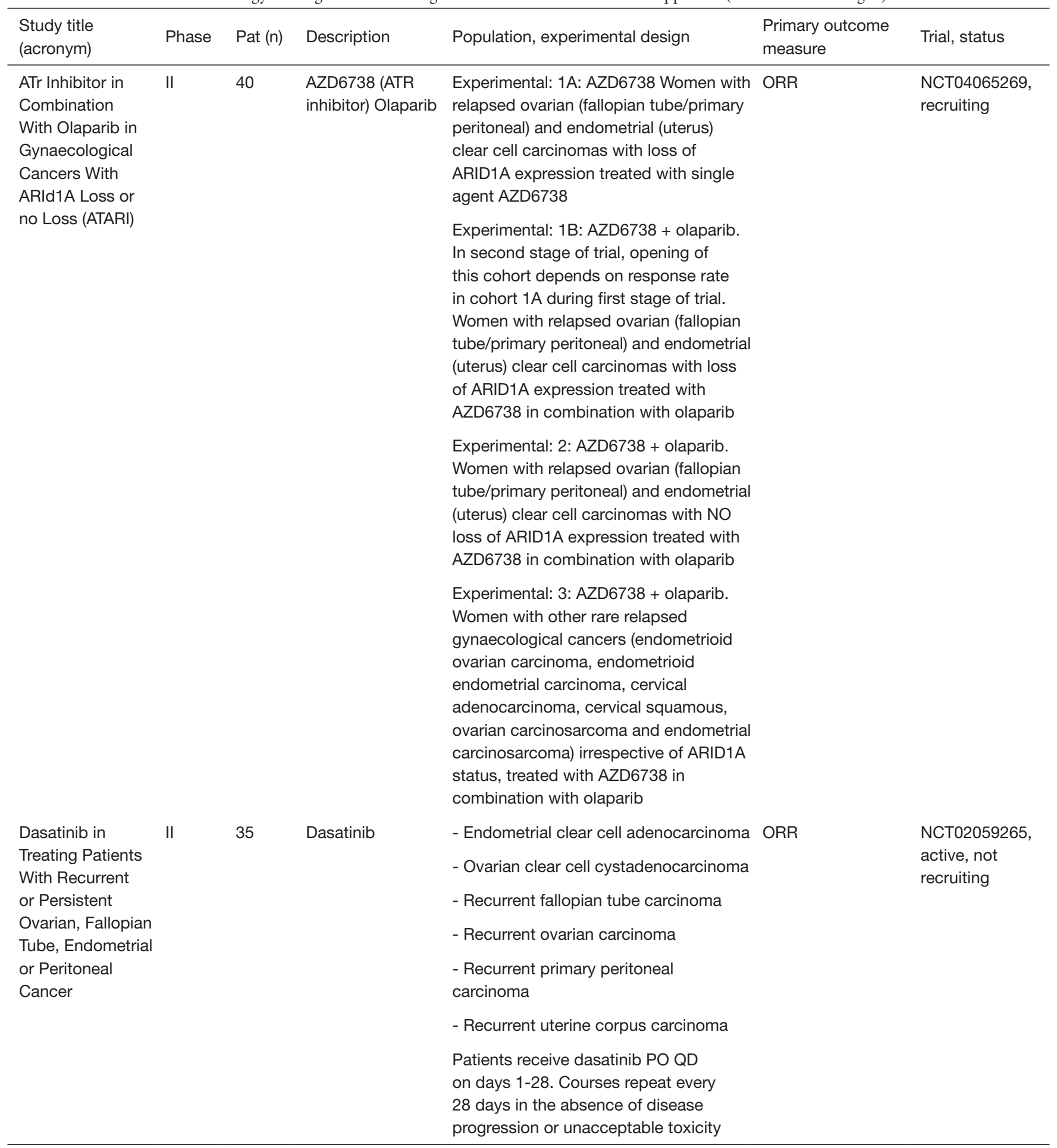

Table 3 (continued) 
Table 3 (continued)

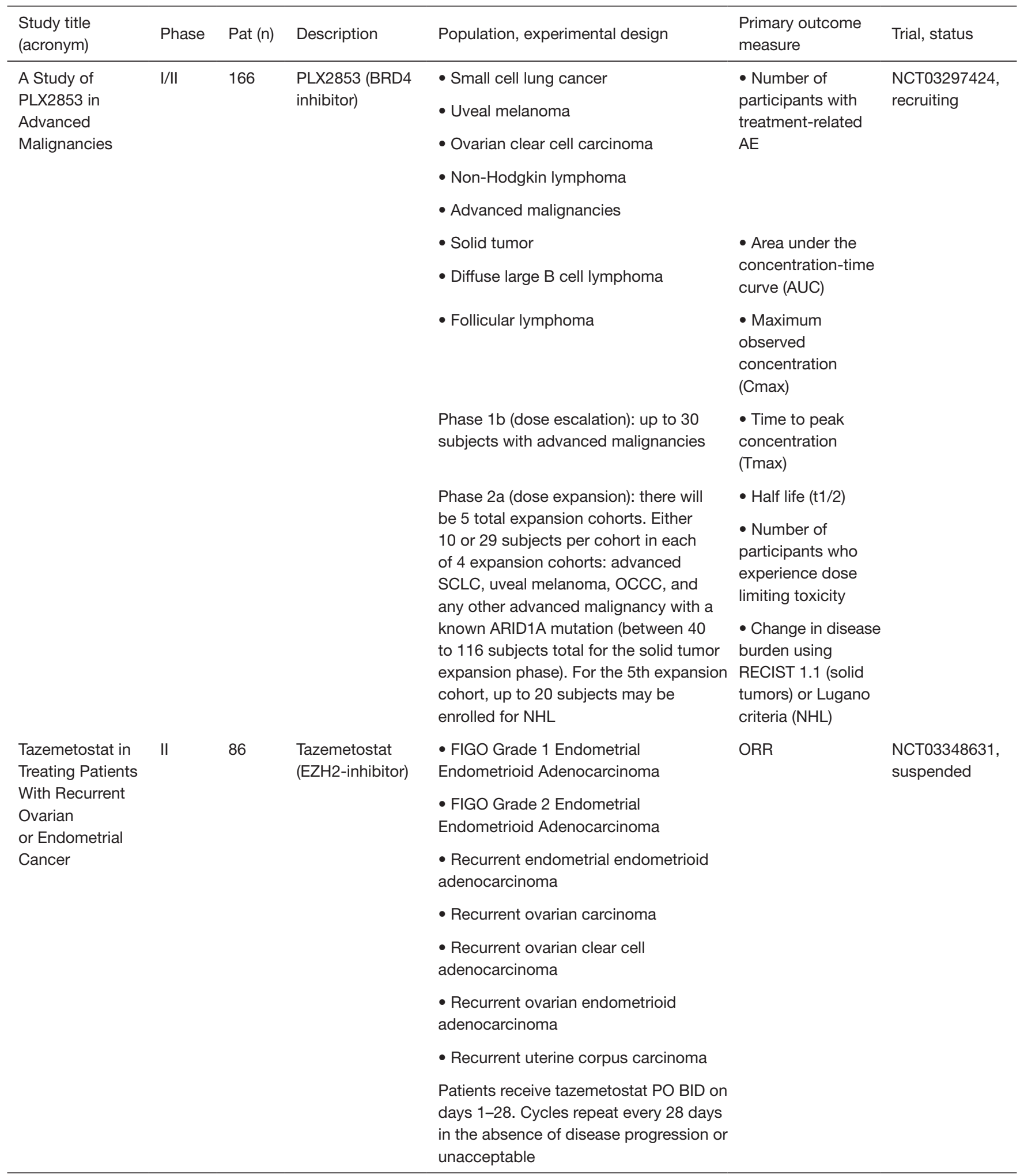

Table 3 (continued) 
Table 3 (continued)

\begin{tabular}{|c|c|c|c|c|c|c|}
\hline $\begin{array}{l}\text { Study title } \\
\text { (acronym) }\end{array}$ & Phase & Pat (n) & Description & Population, experimental design & $\begin{array}{l}\text { Primary outcome } \\
\text { measure }\end{array}$ & Trial, status \\
\hline $\begin{array}{l}\text { A Study of } \\
\text { ENMD-2076 in } \\
\text { Ovarian Clear Cell } \\
\text { Cancers }\end{array}$ & II & 40 & $\begin{array}{l}\text { ENMD-2076 } \\
\text { (oral anti- } \\
\text { angiogenic and } \\
\text { anti-proliferative } \\
\text { kinase inhibitor) }\end{array}$ & $\begin{array}{l}\text { ENMD- } 2067 \text { will be taken orally at a } \\
\text { dose of } 275 \mathrm{mg} \text {, once a day, everyday. } \\
\text { Patients with a body surface area of less } \\
\text { than } 1.65 \mathrm{~m}^{2} \text { will receive a starting dose } \\
\text { of } 250 \mathrm{mg} \text {, once a day, everyday }\end{array}$ & $\begin{array}{l}\text { Six-month } \\
\text { progression free } \\
\text { survival rate } \\
\text { Complete or partial } \\
\text { response rate }\end{array}$ & $\begin{array}{l}\text { NCT01914510, } \\
\text { completed }\end{array}$ \\
\hline
\end{tabular}

OC, ovarian cancer; ORR, overall response rate; MTD, maximum tolerated dose; PFS, progression free survival; OS, overall survival.

based chemotherapies, but the results of the different mainly retrospective studies are conflicting and a possible association remains to be elucidated (135-139).

Besides the very intensively and successfully investigated PARP inhibitors, which have led to a dramatic improvement in the treatment of ovarian cancer and beyond, several clinical trials investigating ATR inhibitors and inhibitors of the PI3K/Akt/mTOR-pathway are currently ongoing in gynecologic cancers, some of them with molecular subanalyses or stratification including ARID1A (Table 3).

In a Phase II trial of everolimus plus bevacizumab in advanced non-clear cell renal cell carcinoma there was a net benefit in tumors with papillary features with an ORR of $43 \%$ vs. $11 \%$, a median PFS of 12.9 vs. 1.9 months, and an overall survival of 28.2 vs. 9.3 months $(\mathrm{P}<0.001)$ compared to non-clear cell renal cell carcinoma without papillary features. Of note, five of the fourteen tumors with papillary features harbored somatic mutations in ARID1A and all five patients achieved treatment benefit (140). In a recently published Phase II trial of everolimus and bevacizumab in recurrent ovarian, peritoneal, and fallopian tube cancer, two of the nine responders were OCCC cases which both harbored mutations in ARID1A and PI3K-mediated activations of the mTOR-pathway. Three other responders had serous ovarian cancer with mutations in the homologous recombination pathway. It was noted that the two OCCC were among the patients staying on treatment for the longest with 11 and 15 cycles of treatment respectively (141). Although the combination of bevacizumab plus everolimus, compared to bevacizumab alone, did not improve PFS or OS in recurrent or persistent ovarian, fallopian tube or peritoneal carcinoma in a randomized Phase II trial (142), these observations indicate a possible benefit in certain subgroups such as ARID1A mutated OCCC.

Dasatinib is already approved for leukemia treatment and is currently under investigation for various solid tumors. A
phase-II trial evaluating dasatinib in recurrent or persistent EOC showed limited efficacy but this study did not assess ARID1A status in the tumors (111).

After the first generation of EZH2 inhibitors have shown toxicity in vivo, novel EZH2 inhibitors are currently the subject of clinical trials (143). Meanwhile, the NRGGY-014 phase II clinical trial assessing the EZH2-inhibitor tazemetostat in recurrent EnOC or OCC, as well as recurrent low-grade endometrioid endometrial carcinoma, is currently recruiting (144).

Other alternatives for epigenetic targeting agents include HDAC2 inhibition, e.g., with vorinostat, or the HDAC6 inhibitor ricolinostat (ACY-1215), which has been well tolerated by patients with relapsed or refractory multiple myeloma in a phase- $1 \mathrm{~b}$ trial $(102,145)$. Furthermore, there is preclinical evidence of synergies between HDACinhibitors and anti-PD-L1 immune checkpoint blockade in ARID1A-deficient ovarian cancer which may be a promising combination to be evaluated in future clinical trials $(146,147)$.

Inhibitors of the BET (bromodomain and extra terminal domain) family of proteins have been shown to inhibit the proliferation of ARID1A-mutated cancer cell lines in vitro as well as in patient-derived xenograft models (104). Several BET inhibitors such as iBET-762 are currently under evaluation in phase I-II trials (148).

Besides target therapies and immunotherapies, the assessment of ARID1A in OCCC patients may also be helpful in the choice of chemotherapy. Gemcitabine appears the most effective chemotherapy agent in platinum-resistant OCCC with response rate estimated to $66 \%(n=12)$ in a sub-group analysis of the MITO-9 study (149). This was confirmed in another small retrospective cohort from Japan $(\mathrm{n}=7)$ that showed that three ARID1A-deficient OCCC patients had a significantly longer progression-free survival with gemcitabine compared to four OCCC patients $(\mathrm{P}=0.02)$ 
Table 4 Some examples of recent or ongoing studies in benign gynecologic disease and cancer including the detection of ARID1A mutations (www. clinicaltrials.gov)

\begin{tabular}{|c|c|c|c|c|c|}
\hline Study title, acronym & Pat $n$ & Description & Population, experimental design & Primary outcome measure & Trial, status \\
\hline $\begin{array}{l}\text { Lavage of the Uterine } \\
\text { Cavity for the Diagnosis } \\
\text { of Ovarian and Tubal } \\
\text { Carcinoma - Study } \\
\text { of Sensitivity and } \\
\text { Specificity (LUDOC II) }\end{array}$ & 540 & Interventional & $\begin{array}{l}\text { Ovarian epithelial cancer } \\
\text { - Procedure: lavage of the } \\
\text { Cavum uteri and proximal } \\
\text { fallopian tubes }\end{array}$ & $\begin{array}{l}\text { Detection of somatic mutation } \\
\text { analysis in at least one of the } \\
\text { analyzed genes in cells found in } \\
\text { the lavage of the uterine cavity } \\
\text { and proximal tubes }\end{array}$ & $\begin{array}{l}\text { NCT02518256, } \\
\text { recruiting }\end{array}$ \\
\hline $\begin{array}{l}\text { Preoperative Olaparib } \\
\text { Endometrial Carcinoma } \\
\text { Study (POLEN) }\end{array}$ & 36 & $\begin{array}{l}\text { Preoperative } \\
\text { "Window of } \\
\text { opportunity" Study } \\
\text { Treatment with } \\
\text { Olaparib }\end{array}$ & $\begin{array}{l}\text { Evaluate the Inhibitory Effects } \\
\text { of Single Agent AZD2281 } \\
\text { (Olaparib), in Patients with Early- } \\
\text { stage Endometrial Carcinoma }\end{array}$ & $\begin{array}{l}\text { Expression of cell cycle-related } \\
\text { proteins }\end{array}$ & $\begin{array}{l}\text { NCT02506816, } \\
\text { completed }\end{array}$ \\
\hline
\end{tabular}

who were not (150).

\section{Conclusions and future implications}

Despite being one of the most frequent benign disease in women of reproductive age, endometriosis remains fairly enigmatic in its cause and even more concerning the factors that in rare cases may lead to malignant transformation. Many unresolved aspects in endometriosis-associated ovarian cancer remain to be addressed. This includes diagnosis and early detection of malignant transformation of endometriosis, identification of risk factors associated with development of ovarian cancer and stratification of women at increased risk. 
Recent knowledge advances about alterations involving the SWI/SNF complex and its subunit ARID1A lead to a better picture of the processes involved in endometriosis and the carcinogenesis of EAOC. The dramatic improvement in ovarian cancer therapy achieved through intensive investigation of PARP inhibitors has undoubtedly boosted the research of new target therapies in ovarian cancer. New approaches are likely to soon translate into clinical research. Since inflammatory and epigenetic processes seem to play a predominant role in the pathogenesis of endometriosisassociated ovarian carcinomas, which mainly account for the subtypes OCCC and EnOC, immune checkpoint inhibitors and targeting the PI3K pathway as well as epigenetic treatment approaches may play an important role in the treatment of these tumor entities. Further clinical research based on the specific molecular features of these tumor subtypes, such as e.g., umbrella or basket trials, will be crucial to elucidate the potential role of these treatment approaches.

\section{Acknowledgments}

The authors would like to thank Carla Trachsel-Holmes for English language editing in the present manuscript.

Funding: None.

\section{Footnote}

Provenance and Peer Review: This article was commissioned by the editorial office, Annals of Translational Medicine for the series "Ovarian Cancer: State of the Art and Perspectives of Clinical Research". The article has undergone external peer review.

Reporting Checklist: The authors have completed the NARRATIVE REVIEW reporting checklist. Available at http://dx.doi.org/10.21037/atm-20-3022a

Conflicts of Interest: All authors have completed the ICMJE uniform disclosure form (available at http://dx.doi. org/10.21037/atm-20-3022a). The series "Ovarian Cancer: State of the Art and Perspectives of Clinical Research" was commissioned by the editorial office without any funding or sponsorship. SB served as the unpaid Guest Editor of the series and serves as an unpaid editorial board member of Annals of Translational Medicine from Nov 2019 to Oct 2021. Dr. SILG reports personal fees from AstraZeneca, grants from Novimmune, outside the submitted work. Dr. JAPF reports grants from Mutua Madrileña, grants from Sociedad
Española de Oncologia Medica (Spanish Society of Medical Oncology), during the conduct of the study; personal fees from AstraZeneca, personal fees from GSK - Tesaro, personal fees from Clovis, personal fees from Roche, personal fees from Amgen, personal fees from Pfizer, personal fees from Pharmamar, outside the submitted work; in addition, Dr. JAPF has a patent Predictive signature for neoadjuvant chemotherapy in breast cancer pending. The authors have no other conflicts of interest to declare.

Ethical Statement: The authors are accountable for all aspects of the work in ensuring that questions related to the accuracy or integrity of any part of the work are appropriately investigated and resolved.

Open Access Statement: This is an Open Access article distributed in accordance with the Creative Commons Attribution-NonCommercial-NoDerivs 4.0 International License (CC BY-NC-ND 4.0), which permits the noncommercial replication and distribution of the article with the strict proviso that no changes or edits are made and the original work is properly cited (including links to both the formal publication through the relevant DOI and the license). See: https://creativecommons.org/licenses/by-nc-nd/4.0/.

\section{References}

1. Zondervan KT, Becker CM, Missmer SA. Endometriosis. N Engl J Med 2020;382:1244-56.

2. Giudice LC. Clinical practice. Endometriosis. N Engl J Med 2010;362:2389-98.

3. Bulun SE. Endometriosis. N Engl J Med 2009;360:268-79.

4. Buck Louis GM, Hediger ML, Peterson CM, et al. Incidence of endometriosis by study population and diagnostic method: the ENDO study. Fertil Steril 2011;96:360-5.

5. Geng JH, Lee YC. Bladder Endometriosis. N Engl J Med 2019;381:e43.

6. Wiegand KC, Shah SP, Al-Agha OM, et al. ARID1A mutations in endometriosis-associated ovarian carcinomas. N Engl J Med 2010;363:1532-43.

7. Jones S, Wang TL, Shih Ie M, et al. Frequent mutations of chromatin remodeling gene ARID1A in ovarian clear cell carcinoma. Science 2010;330:228-31.

8. Sugiyama T, Kamura T, Kigawa J, et al. Clinical characteristics of clear cell carcinoma of the ovary: a distinct histologic type with poor prognosis and resistance to platinum-based chemotherapy. Cancer 2000;88:2584-9. 
9. Köbel M, Kalloger SE, Huntsman DG, et al. Differences in tumor type in low-stage versus high-stage ovarian carcinomas. Int J Gynecol Pathol 2010;29:203-11.

10. Park HK, Ruterbusch JJ, Cote ML. Recent Trends in Ovarian Cancer Incidence and Relative Survival in the United States by Race/Ethnicity and Histologic Subtypes. Cancer Epidemiol Biomarkers Prev 2017;26:1511-8.

11. Wang S, Qiu L, Lang JH, et al. Prognostic analysis of endometrioid epithelial ovarian cancer with or without endometriosis: a 12-year cohort study of Chinese patients. Am J Obstet Gynecol 2013;209:241.e1-9.

12. Chan JK, Teoh D, Hu JM, et al. Do clear cell ovarian carcinomas have poorer prognosis compared to other epithelial cell types? A study of 1411 clear cell ovarian cancers. Gynecol Oncol 2008;109:370-6.

13. Lheureux S, Gourley C, Vergote I, et al. Epithelial ovarian cancer. Lancet 2019;393:1240-53.

14. Harter P, Sehouli J, Lorusso D, et al. A Randomized Trial of Lymphadenectomy in Patients with Advanced Ovarian Neoplasms. N Engl J Med 2019;380:822-32.

15. Colombo PE, Fabbro M, Theillet C, et al. Sensitivity and resistance to treatment in the primary management of epithelial ovarian cancer. Crit Rev Oncol Hematol 2014;89:207-16.

16. Foster W. Diagnosing endometriosis: CA125 rules in, but not out. BJOG 2016;123:1769.

17. Muyldermans M, Cornillie FJ, Koninckx PR. CA125 and endometriosis. Hum Reprod Update 1995;1:173-87.

18. O DF, Flores I, Waelkens E, et al. Noninvasive diagnosis of endometriosis: Review of current peripheral blood and endometrial biomarkers. Best Pract Res Clin Obstet Gynaecol 2018;50:72-83.

19. Tanase Y, Kawaguchi R, Takahama J, et al. Factors that Differentiate between Endometriosis-associated Ovarian Cancer and Benign Ovarian Endometriosis with Mural Nodules. Magn Reson Med Sci 2018;17:231-7.

20. Moro F, Magoga G, Pasciuto T, et al. Imaging in gynecological disease (13): clinical and ultrasound characteristics of endometrioid ovarian cancer. Ultrasound Obstet Gynecol 2018;52:535-43.

21. Vercellini P, Vigano P, Buggio L, et al. Perimenopausal management of ovarian endometriosis and associated cancer risk: When is medical or surgical treatment indicated? Best Pract Res Clin Obstet Gynaecol 2018;51:151-68.

22. Sasaki A, Akita K, Ito F, et al. Difference in mesothelinbinding ability of serum CA125 between patients with endometriosis and epithelial ovarian cancer. Int J Cancer 2015;136:1985-90.

23. Konrad L, Dietze R, Kudipudi PK, et al. Endometriosis in MRKH cases as a proof for the coelomic metaplasia hypothesis? Reproduction 2019;158:R41-7.

24. Mechsner S, Weichbrodt M, Riedlinger WFJ, et al. Immunohistochemical evaluation of endometriotic lesions and disseminated endometriosis-like cells in incidental lymph nodes of patients with endometriosis. Fertility and Sterility 2010;94:457-63.

25. Keichel S, Barcena de Arellano ML, Reichelt U, et al. Lymphangiogenesis in deep infiltrating endometriosis. Hum Reprod 2011;26:2713-20.

26. Chui MH, Wang TL, Shih IM. Endometriosis: benign, malignant, or something in between? Oncotarget 2017;8:78263-4.

27. Taylor HS, Giudice LC, Lessey BA, et al. Treatment of Endometriosis-Associated Pain with Elagolix, an Oral GnRH Antagonist. N Engl J Med 2017;377:28-40.

28. Somigliana E, Vigano' P, Parazzini F, et al. Association between endometriosis and cancer: a comprehensive review and a critical analysis of clinical and epidemiological evidence. Gynecol Oncol 2006;101:331-41.

29. Samartzis EP, Samartzis N, Noske A, et al. Loss of ARID1A/BAF250a-expression in endometriosis: a biomarker for risk of carcinogenic transformation? Mod Pathol 2012;25:885-92.

30. Anglesio MS, Papadopoulos N, Ayhan A, et al. CancerAssociated Mutations in Endometriosis without Cancer. N Engl J Med 2017;376:1835-48.

31. Montgomery GW, Mortlock S, Giudice LC. Should Genetics Now Be Considered the Pre-eminent Etiologic Factor in Endometriosis? J Minim Invasive Gynecol 2020;27:280-6.

32. Wilson MR, Holladay J, Chandler RL. A mouse model of endometriosis mimicking the natural spread of invasive endometrium. Hum Reprod 2020;35:58-69.

33. Xu G, Chhangawala S, Cocco E, et al. ARID1A determines luminal identity and therapeutic response in estrogenreceptor-positive breast cancer. Nat Genet 2020;52:198-207.

34. Nagarajan S, Rao SV, Sutton J, et al. ARID1A influences HDAC1/BRD4 activity, intrinsic proliferative capacity and breast cancer treatment response. Nat Genet 2020;52:187-197.

35. Sampson JA. Endometrial carcinoma of the ovary, arising in endometrial tissue in that organ. Arch Surg 1925;10:1-72.

36. Vercellini P, Parazzini F, Bolis G, et al. Endometriosis and ovarian cancer. Am J Obstet Gynecol 1993;169:181-2.

37. Venn A, Watson L, Bruinsma F, et al. Risk of cancer after use of fertility drugs with in-vitro fertilisation. Lancet 
1999;354:1586-90.

38. Ness RB, Grisso JA, Cottreau C, et al. Factors related to inflammation of the ovarian epithelium and risk of ovarian cancer. Epidemiology 2000;11:111-7.

39. Ness RB, Cramer DW, Goodman MT, et al. Infertility, fertility drugs, and ovarian cancer: a pooled analysis of case-control studies. Am J Epidemiol 2002;155:217-24.

40. Borgfeldt C, Andolf E. Cancer risk after hospital discharge diagnosis of benign ovarian cysts and endometriosis. Acta Obstet Gynecol Scand 2004;83:395-400.

41. Brinton LA, Lamb EJ, Moghissi KS, et al. Ovarian cancer risk associated with varying causes of infertility. Fertil Steril 2004;82:405-14.

42. Brinton LA, Sakoda LC, Sherman ME, et al. Relationship of benign gynecologic diseases to subsequent risk of ovarian and uterine tumors. Cancer Epidemiol Biomarkers Prev 2005;14:2929-35.

43. Kobayashi H, Sumimoto K, Moniwa N, et al. Risk of developing ovarian cancer among women with ovarian endometrioma: a cohort study in Shizuoka, Japan. Int J Gynecol Cancer 2007;17:37-43.

44. Merritt MA, Green AC, Nagle CM, et al. Talcum powder, chronic pelvic inflammation and NSAIDs in relation to risk of epithelial ovarian cancer. Int J Cancer 2008;122:170-6.

45. Rossing MA, Cushing-Haugen KL, Wicklund KG, et al. Risk of epithelial ovarian cancer in relation to benign ovarian conditions and ovarian surgery. Cancer Causes Control 2008;19:1357-64.

46. Wu AH, Pearce CL, Tseng CC, et al. Markers of inflammation and risk of ovarian cancer in Los Angeles County. Int J Cancer 2009;124:1409-15.

47. Brinton LA, Gridley G, Persson I, et al. Cancer risk after a hospital discharge diagnosis of endometriosis. Am J Obstet Gynecol 1997;176:572-9.

48. Melin A, Sparén P, Persson I, et al. Endometriosis and the risk of cancer with special emphasis on ovarian cancer. Hum Reprod 2006;21:1237-42.

49. Pearce CL, Templeman C, Rossing MA, et al. Association between endometriosis and risk of histological subtypes of ovarian cancer: a pooled analysis of case-control studies. Lancet Oncol 2012;13:385-94.

50. Mogensen JB, Kjaer SK, Mellemkjaer L, et al. Endometriosis and risks for ovarian, endometrial and breast cancers: A nationwide cohort study. Gynecol Oncol 2016;143:87-92.

51. Hermens M, van Altena AM, Nieboer TE, et al. Incidence of endometrioid and clear-cell ovarian cancer in histological proven endometriosis. The ENOCA population-based cohort study. Am J Obstet Gynecol 2020;223:107.e1-107.e11.

52. Poole EM, Lin WT, Kvaskoff M, et al. Endometriosis and risk of ovarian and endometrial cancers in a large prospective cohort of U.S. nurses. Cancer Causes Control 2017;28:437-45.

53. Kalaitzopoulos DR, Mitsopoulou A, Iliopoulou SM, et al. Association between endometriosis and gynecological cancers: a critical review of the literature. Arch Gynecol Obstet 2020;301:355-67.

54. Exacoustos C, Manganaro L, Zupi E. Imaging for the evaluation of endometriosis and adenomyosis. Best Pract Res Clin Obstet Gynaecol 2014;28:655-81.

55. Guerriero S, Condous G, van den Bosch T, et al. Systematic approach to sonographic evaluation of the pelvis in women with suspected endometriosis, including terms, definitions and measurements: a consensus opinion from the International Deep Endometriosis Analysis (IDEA) group. Ultrasound Obstet Gynecol 2016;48:318-32.

56. Guerriero S, Van Calster B, Somigliana E, et al. Agerelated differences in the sonographic characteristics of endometriomas. Hum Reprod 2016;31:1723-31.

57. Kobayashi H, Sumimoto K, Kitanaka T, et al. Ovarian endometrioma--risks factors of ovarian cancer development. Eur J Obstet Gynecol Reprod Biol 2008;138:187-93.

58. Thomsen LH, Schnack TH, Buchardi K, et al. Risk factors of epithelial ovarian carcinomas among women with endometriosis: a systematic review. Acta Obstet Gynecol Scand 2017;96:761-78.

59. Moore L, Leongamornlert D, Coorens THH, et al. The mutational landscape of normal human endometrial epithelium. Nature 2020;580:640-6.

60. Suda K, Nakaoka H, Yoshihara K, et al. Clonal Expansion and Diversification of Cancer-Associated Mutations in Endometriosis and Normal Endometrium. Cell Rep 2018;24:1777-89.

61. Lac V, Nazeran TM, Tessier-Cloutier B, et al. Oncogenic mutations in histologically normal endometrium: the new normal? J Pathol 2019;249:173-81.

62. Lac V, Verhoef L, Aguirre-Hernandez R, et al. Iatrogenic endometriosis harbors somatic cancer-driver mutations. Hum Reprod 2019;34:69-78.

63. Wang Y, Li L, Douville C, et al. Evaluation of liquid from the Papanicolaou test and other liquid biopsies for the detection of endometrial and ovarian cancers. Sci Transl Med 2018;10:eaap8793.

64. Kinde I, Bettegowda C, Wang Y, et al. Evaluation of DNA from the Papanicolaou test to detect ovarian and 
endometrial cancers. Sci Transl Med 2013;5:167ra4.

65. Maritschnegg E, Heitz F, Pecha N, et al. Uterine and Tubal Lavage for Earlier Cancer Detection Using an Innovative Catheter: A Feasibility and Safety Study. Int J Gynecol Cancer 2018;28:1692-8.

66. Maritschnegg E, Wang Y, Pecha N, et al. Lavage of the Uterine Cavity for Molecular Detection of Mullerian Duct Carcinomas: A Proof-of-Concept Study. J Clin Oncol 2015;33:4293-300.

67. Shain AH, Pollack JR. The Spectrum of SWI/SNF Mutations, Ubiquitous in Human Cancers. PLoS One 2013;8:e55119.

68. Guan B, Mao TL, Panuganti PK, et al. Mutation and loss of expression of ARID1A in uterine low-grade endometrioid carcinoma. Am J Surg Pathol 2011;35:625-32.

69. Wiegand KC, Lee AF, Al-Agha OM, et al. Loss of BAF250a (ARID1A) is frequent in high-grade endometrial carcinomas. J Pathol 2011;224:328-33.

70. Birnbaum DJ, Adélaïde J, Mamessier E, et al. Genome profiling of pancreatic adenocarcinoma. Genes Chromosomes Cancer 2011;50:456-65.

71. Shain AH, Giacomini CP, Matsukuma K, et al. Convergent structural alterations define SWItch/Sucrose NonFermentable (SWI/SNF) chromatin remodeler as a central tumor suppressive complex in pancreatic cancer. Proc Natl Acad Sci U S A 2012;109:E252-9.

72. Wang K, Kan J, Yuen ST, et al. Exome sequencing identifies frequent mutation of ARID1A in molecular subtypes of gastric cancer. Nat Genet 2011;43:1219-23.

73. Abe H, Maeda D, Hino R, et al. ARID1A expression loss in gastric cancer: pathway-dependent roles with and without Epstein-Barr virus infection and microsatellite instability. Virchows Arch 2012;461:367-77.

74. Zang ZJ, Cutcutache I, Poon SL, et al. Exome sequencing of gastric adenocarcinoma identifies recurrent somatic mutations in cell adhesion and chromatin remodeling genes. Nat Genet 2012;44:570-4.

75. Fujimoto A, Totoki Y, Abe T, et al. Whole-genome sequencing of liver cancers identifies etiological influences on mutation patterns and recurrent mutations in chromatin regulators. Nat Genet 2012;44:760-4.

76. Guichard C, Amaddeo G, Imbeaud S, et al. Integrated analysis of somatic mutations and focal copy-number changes identifies key genes and pathways in hepatocellular carcinoma. Nat Genet 2012;44:694-8.

77. Huang J, Deng Q, Wang Q, et al. Exome sequencing of hepatitis B virus-associated hepatocellular carcinoma. Nat Genet 2012;44:1117-21.
78. Jones S, Li M, Parsons DW, et al. Somatic mutations in the chromatin remodeling gene ARID1A occur in several tumor types. Hum Mutat 2012;33:100-3.

79. Mamo A, Cavallone L, Tuzmen S, et al. An integrated genomic approach identifies ARID1A as a candidate tumor-suppressor gene in breast cancer. Oncogene 2012;31:2090-100.

80. Wang Y, Hoang L, Ji JX, et al. SWI/SNF Complex Mutations in Gynecologic Cancers: Molecular Mechanisms and Models. Annu Rev Pathol 2020;15:467-92.

81. Ayhan A, Mao TL, Seckin T, et al. Loss of ARID1A expression is an early molecular event in tumor progression from ovarian endometriotic cyst to clear cell and endometrioid carcinoma. Int J Gynecol Cancer 2012;22:1310-5.

82. Mao TL, Ardighieri L, Ayhan A, et al. Loss of ARID1A expression correlates with stages of tumor progression in uterine endometrioid carcinoma. Am J Surg Pathol 2013;37:1342-8.

83. Wu JN, Roberts CW. ARID1A mutations in cancer: another epigenetic tumor suppressor? Cancer Discov 2013;3:35-43.

84. Chandler RL, Brennan J, Schisler JC, et al. ARID1a-DNA interactions are required for promoter occupancy by SWI/ SNF. Mol Cell Biol 2013;33:265-80.

85. Kadam S, McAlpine GS, Phelan ML, et al. Functional selectivity of recombinant mammalian SWI/SNF subunits. Genes Dev 2000;14:2441-51.

86. Borrelli GM, Abrao MS, Taube ET, et al. (Partial) Loss of BAF250a (ARID1A) in rectovaginal deep-infiltrating endometriosis, endometriomas and involved pelvic sentinel lymph nodes. Mol Hum Reprod 2016;22:329-37.

87. Chene G, Ouellet V, Rahimi K, et al. The ARID1A pathway in ovarian clear cell and endometrioid carcinoma, contiguous endometriosis, and benign endometriosis. Int J Gynaecol Obstet 2015;130:27-30.

88. Kim TH, Yoo JY, Wang Z, et al. ARID1A Is Essential for Endometrial Function during Early Pregnancy. PLoS Genet 2015;11:e1005537.

89. Wiegand KC, Hennessy BT, Leung S, et al. A functional proteogenomic analysis of endometrioid and clear cell carcinomas using reverse phase protein array and mutation analysis: protein expression is histotype-specific and loss of ARID1A/BAF250a is associated with AKT phosphorylation. BMC Cancer 2014;14:120.

90. Samartzis EP, Noske A, Dedes KJ, et al. ARID1A mutations and PI3K/AKT pathway alterations in endometriosis and endometriosis-associated ovarian carcinomas. Int J Mol Sci 2013;14:18824-49.

91. Yamamoto S, Tsuda H, Takano M, et al. Loss of ARID1A 
protein expression occurs as an early event in ovarian clear-cell carcinoma development and frequently coexists with PIK3CA mutations. Mod Pathol 2012;25:615-24.

92. Guan B, Rahmanto YS, Wu RC, et al. Roles of deletion of Arid1a, a tumor suppressor, in mouse ovarian tumorigenesis. J Natl Cancer Inst 2014;106:dju146.

93. Bosse T, Ter Haar NT, Seeber LM, et al. Loss of ARID1A expression and its relationship with PI3K-Akt pathway alterations, TP53 and microsatellite instability in endometrial cancer. Mod Pathol 2013;26:1525-35.

94. Liang H, Cheung LW, Li J, et al. Whole-exome sequencing combined with functional genomics reveals novel candidate driver cancer genes in endometrial cancer. Genome Res 2012;22:2120-9.

95. Khalique S, Naidoo K, Attygalle AD, et al. Optimised ARID1A immunohistochemistry is an accurate predictor of ARID1A mutational status in gynaecological cancers. J Pathol Clin Res 2018;4:154-66.

96. Pierson WE, Peters PN, Chang MT, et al. An integrated molecular profile of endometrioid ovarian cancer. Gynecol Oncol 2020;157:55-61.

97. Guan B, Wang TL, Shih IM. ARID1A, a factor that promotes formation of SWI/SNF-mediated chromatin remodeling, is a tumor suppressor in gynecologic cancers. Cancer Res 2011;71:6718-27.

98. Bitler BG, Aird KM, Zhang R. Epigenetic synthetic lethality in ovarian clear cell carcinoma: EZH2 and ARID1A mutations. Mol Cell Oncol 2015;3:e1032476.

99. Miller RE, Brough R, Bajrami I, et al. Synthetic Lethal Targeting of ARID1A-Mutant Ovarian Clear Cell Tumors with Dasatinib. Mol Cancer Ther 2016;15:1472-84.

100. Samartzis EP, Gutsche K, Dedes KJ, et al. Loss of ARID1A expression sensitizes cancer cells to PI3K-and AKT-inhibition. Oncotarget 2014;5:5295-303.

101.Pfister SX, Ashworth A. Marked for death: targeting epigenetic changes in cancer. Nat Rev Drug Discov 2017;16:241-63.

102. Fukumoto T, Park PH, Wu S, et al. Repurposing PanHDAC Inhibitors for ARID1A-Mutated Ovarian Cancer. Cell Rep 2018;22:3393-400.

103. Bitler BG, Wu S, Park PH, et al. ARID1A-mutated ovarian cancers depend on HDAC6 activity. Nat Cell Biol 2017;19:962-73

104. Berns K, Caumanns JJ, Hijmans EM, et al. ARID1A mutation sensitizes most ovarian clear cell carcinomas to BET inhibitors. Oncogene 2018;37:4611-25.

105.Helming KC, Wang X, Wilson BG, et al. ARID1B is a specific vulnerability in ARID1A-mutant cancers. Nat Med
2014;20:251-4.

106. Bitler BG, Aird KM, Garipov A, et al. Synthetic lethality by targeting EZH2 methyltransferase activity in ARID1Amutated cancers. Nat Med 2015;21:231-8.

107. Bitler BG, Fatkhutdinov N, Zhang R. Potential therapeutic targets in ARID1A-mutated cancers. Expert Opin Ther Targets 2015;19:1419-22.

108. Caumanns JJ, Berns K, Wisman GBA, et al. Integrative Kinome Profiling Identifies mTORC1/2 Inhibition as Treatment Strategy in Ovarian Clear Cell Carcinoma. Clin Cancer Res 2018;24:3928.

109. Kashiyama T, Oda K, Ikeda Y, et al. Antitumor activity and induction of TP53-dependent apoptosis toward ovarian clear cell adenocarcinoma by the dual PI3K/mTOR inhibitor DS-7423. PLoS One 2014;9:e87220.

110. Oda K, Ikeda Y, Kashiyama T, et al. Characterization of TP53 and PI3K signaling pathways as molecular targets in gynecologic malignancies. J Obstet Gynaecol Res 2016;42:757-62.

111. Schilder RJ, Brady WE, Lankes HA, et al. Phase II evaluation of dasatinib in the treatment of recurrent or persistent epithelial ovarian or primary peritoneal carcinoma: a Gynecologic Oncology Group study. Gynecol Oncol 2012;127:70-4.

112. Secord AA, Teoh DK, Barry WT, et al. A phase I trial of dasatinib, an SRC-family kinase inhibitor, in combination with paclitaxel and carboplatin in patients with advanced or recurrent ovarian cancer. Clin Cancer Res 2012;18:5489-98.

113. Williamson CT, Miller R, Pemberton HN, et al. ATR inhibitors as a synthetic lethal therapy for tumours deficient in ARID1A. Nat Commun 2016;7:13837.

114. Shen J, Peng Y, Wei L, et al. ARID1A Deficiency Impairs the DNA Damage Checkpoint and Sensitizes Cells to PARP Inhibitors. Cancer Discov 2015;5:752-67.

115. Chandler RL, Damrauer JS, Raab JR, et al. Coexistent ARID1A-PIK3CA mutations promote ovarian clear-cell tumorigenesis through pro-tumorigenic inflammatory cytokine signalling. Nat Commun 2015;6:6118.

116. Ogiwara H, Takahashi K, Sasaki M, et al. Targeting the Vulnerability of Glutathione Metabolism in ARID1ADeficient Cancers. Cancer Cell 2019;35:177-90.e8.

117.Jelinic P, Ricca J, Van Oudenhove E, et al. Immune-Active Microenvironment in Small Cell Carcinoma of the Ovary, Hypercalcemic Type: Rationale for Immune Checkpoint Blockade. J Natl Cancer Inst 2018;110:787-90.

118. Shen J, Ju Z, Zhao W, et al. ARID1A deficiency promotes mutability and potentiates therapeutic antitumor immunity 
unleashed by immune checkpoint blockade. Nat Med 2018;24:556-62.

119.Anglesio MS, Carey MS, Köbel M, et al. Clear cell carcinoma of the ovary: a report from the first Ovarian Clear Cell Symposium, June 24th, 2010. Gynecol Oncol 2011;121:407-15.

120. Yamamoto S, Tsuda H, Takano M, et al. PIK3CA mutations and loss of ARID1A protein expression are early events in the development of cystic ovarian clear cell adenocarcinoma. Virchows Arch 2012;460:77-87.

121. Matsuo K, Hasegawa K, Yoshino K, et al. Venous thromboembolism, interleukin-6 and survival outcomes in patients with advanced ovarian clear cell carcinoma. Eur J Cancer 2015;51:1978-88.

122. Kawabata A, Yanaihara N, Nagata C, et al. Prognostic impact of interleukin-6 expression in stage I ovarian clear cell carcinoma. Gynecol Oncol 2017;146:609-14.

123. Miao D, Margolis CA, Gao W, et al. Genomic correlates of response to immune checkpoint therapies in clear cell renal cell carcinoma. Science 2018;359:801-6.

124. Hamanishi J, Mandai M, Ikeda T, et al. Safety and Antitumor Activity of Anti-PD-1 Antibody, Nivolumab, in Patients With Platinum-Resistant Ovarian Cancer. J Clin Oncol 2015;33:4015-22.

125. Matulonis UA, Shapira-Frommer R, Santin AD, et al. Antitumor activity and safety of pembrolizumab in patients with advanced recurrent ovarian cancer: results from the phase II KEYNOTE-100 study. Ann Oncol 2019;30:1080-7.

126. Park JH, Park EJ, Lee HS, et al. Mammalian SWI/ SNF complexes facilitate DNA double-strand break repair by promoting gamma-H2AX induction. EMBO J 2006;25:3986-97.

127.Zhao B, Lin J, Rong L, et al. ARID1A promotes genomic stability through protecting telomere cohesion. Nat Commun 2019;10:4067.

128. Thorpe GW, Fong CS, Alic N, et al. Cells have distinct mechanisms to maintain protection against different reactive oxygen species: oxidative-stress-response genes. Proc Natl Acad Sci U S A 2004;101:6564-9.

129. Riedel CG, Dowen RH, Lourenco GF, et al. DAF16 employs the chromatin remodeller SWI/SNF to promote stress resistance and longevity. Nat Cell Biol 2013; 15:491-501.

130. Vercellini P, Crosignani P, Somigliana E, et al. The 'incessant menstruation' hypothesis: a mechanistic ovarian cancer model with implications for prevention. Hum Reprod 2011;26:2262-73.
131. Kwan SY, Cheng X, Tsang YT, et al. Loss of ARID1A expression leads to sensitivity to ROS-inducing agent elesclomol in gynecologic cancer cells. Oncotarget 2016;7:56933-43.

132. Gorrini C, Mak TW. Glutathione Metabolism: An Achilles' Heel of ARID1A-Deficient Tumors. Cancer Cell 2019;35:161-3.

133. Gorrini C, Harris IS, Mak TW. Modulation of oxidative stress as an anticancer strategy. Nat Rev Drug Discov 2013;12:931-47.

134. Khalique S, Lord CJ, Banerjee S, et al. Translational genomics of ovarian clear cell carcinoma. Semin Cancer Biol 2020;61:121-31.

135. Katagiri A, Nakayama K, Rahman MT, et al. Loss of ARID1A expression is related to shorter progressionfree survival and chemoresistance in ovarian clear cell carcinoma. Mod Pathol 2012;25:282-8.

136. Yokoi A, Matsumoto T, Watanabe G, et al. Immunophenotypic profile as a predictor of prognosis in advanced ovarian carcinoma. Hum Pathol 2019;85:210-20.

137.Heckl M, Schmoeckel E, Hertlein L, et al. The ARID1A, p53 and ss-Catenin statuses are strong prognosticators in clear cell and endometrioid carcinoma of the ovary and the endometrium. PLoS One 2018;13:e0192881.

138. Uehara Y, Oda K, Ikeda Y, et al. Integrated copy number and expression analysis identifies profiles of whole-arm chromosomal alterations and subgroups with favorable outcome in ovarian clear cell carcinomas. PLoS One 2015;10:e0128066.

139. Yokoyama Y, Matsushita Y, Shigeto T, et al. Decreased ARID1A expression is correlated with chemoresistance in epithelial ovarian cancer. J Gynecol Oncol 2014;25:58-63.

140. Voss MH, Molina AM, Chen YB, et al. Phase II Trial and Correlative Genomic Analysis of Everolimus Plus Bevacizumab in Advanced Non-Clear Cell Renal Cell Carcinoma. J Clin Oncol 2016;34:3846-53.

141. Taylor SE, Chu T, Elvin JA, et al. Phase II study of everolimus and bevacizumab in recurrent ovarian, peritoneal, and fallopian tube cancer. Gynecol Oncol 2020;156:32-7.

142. Tew WP, Sill MW, Walker JL, et al. Randomized phase II trial of bevacizumab plus everolimus versus bevacizumab alone for recurrent or persistent ovarian, fallopian tube or peritoneal carcinoma: An NRG oncology/gynecologic oncology group study. Gynecol Oncol 2018;151:257-63.

143. Kim KH, Roberts CW. Targeting EZH2 in cancer. Nat Med 2016;22:128-34.

144.Lee JM, Minasian L, Kohn EC. New strategies in ovarian cancer treatment. Cancer 2019;125 Suppl 24:4623-9. 


\section{Page 20 of 20}

145. Yee AJ, Bensinger WI, Supko JG, et al. Ricolinostat plus lenalidomide, and dexamethasone in relapsed or refractory multiple myeloma: a multicentre phase $1 \mathrm{~b}$ trial. Lancet Oncol 2016;17:1569-78.

146. Fukumoto T, Fatkhutdinov N, Zundell JA, et al. HDAC6 Inhibition Synergizes with Anti-PD-L1 Therapy in ARID1AInactivated Ovarian Cancer. Cancer Res 2019;79:5482-9.

147. Yano M, Katoh T, Miyazawa M, et al. Clinicopathological correlation of ARID1A status with HDAC6 and its related factors in ovarian clear cell carcinoma. Sci Rep 2019;9:2397. 148. Caumanns JJ, Wisman GBA, Berns K, et al. ARID1A

Cite this article as: Samartzis EP, Labidi-Galy SI, Moschetta M, Uccello M, Kalaitzopoulos DR, Perez-Fidalgo JA, Boussios S. Endometriosis-associated ovarian carcinomas: insights into pathogenesis, diagnostics, and therapeutic targets-a narrative review. Ann Transl Med 2020;8(24):1712. doi: 10.21037/atm20-3022a
Samartzis et al. Endometriosis-associated ovarian carcinomas

mutant ovarian clear cell carcinoma: A clear target for synthetic lethal strategies. Biochim Biophys Acta Rev Cancer 2018;1870:176-84.

149. Esposito F, Cecere SC, Magazzino F, et al. Second-line chemotherapy in recurrent clear cell ovarian cancer: results from the multicenter italian trials in ovarian cancer (MITO-9). Oncology 2014;86:351-8.

150.Kuroda T, Ogiwara H, Sasaki M, et al. Therapeutic preferability of gemcitabine for ARID1A-deficient ovarian clear cell carcinoma. Gynecol Oncol 2019;155:489-98. 